\title{
Additional effect of azithromycin over $\beta$-lactam alone for severe community- acquired pneumonia-associated acute respiratory distress syndrome: a retrospective cohort study
}

Jun Suzuki ${ }^{1 *} \mathbb{D}$, Yusuke Sasabuchi ${ }^{2}$, Shuji Hatakeyama ${ }^{1,3}$, Hiroki Matsui ${ }^{4}$, Teppei Sasahara ${ }^{1,5}$, Yuji Morisawa ${ }^{1}$, Toshiyuki Yamada ${ }^{6}$, Kiyohide Fushimi ${ }^{7}$ and Hideo Yasunaga ${ }^{4}$

\begin{abstract}
Background: Community-acquired pneumonia (CAP) is the most common cause of acute respiratory distress syndrome (ARDS). Although previous studies have suggested that macrolide therapy is beneficial for ARDS, its benefit for severe CAP-associated ARDS remains uncertain. Previous studies were limited in that they had a small sample size and included patients with non-pulmonary ARDS and those with pulmonary ARDS. This study aimed to investigate the additional effect of azithromycin when used with $\beta$-lactam compared with the effect of $\beta$-lactam alone in mechanically ventilated patients with CAP-associated ARDS.

Methods: We identified mechanically ventilated patients with CAP-associated ARDS between July 2010 and March 2015 using data in the Diagnosis Procedure Combination database, a Japanese nationwide inpatient database. We performed propensity score matching analysis to assess 28-day mortality and in-hospital mortality in mechanically ventilated patients with CAP-associated ARDS who received $\beta$-lactam with and without azithromycin within hospital 2 days after admission. The inverse probability of treatment weighting analysis was also conducted.

Results: Eligible patients $(n=1257)$ were divided into the azithromycin group $(n=226)$ and the control group $(n=1031)$. The one-to-four propensity score matching analysis included 139 azithromycin users and 556 non-users. No significant difference was observed between the groups with respect to 28 -day mortality (34.5\% vs. 37.6\%, $p=0.556$ ) or in-hospital mortality ( $46.0 \%$ vs. $49.1 \%, p=0.569)$. The inverse probability of treatment weighting analysis showed similar results.

Conclusions: Compared with treatment with $\beta$-lactam alone, treatment with azithromycin plus $\beta$-lactam had no significant additional effect on 28-day mortality or in-hospital mortality in mechanically ventilated patients with CAP-associated ARDS. To the best of our knowledge, this study is the first to determine the effect of azithromycin in mechanically ventilated patients with CAP-associated ARDS.
\end{abstract}

Keywords: Severe pneumonia, Azithromycin, Mortality, ARDS

*Correspondence: j-suzuki@tohoku-mpu.ac.jp

${ }^{1}$ Division of Infectious Diseases, Jichi Medical University Hospital, 3311-1

Yakushiji, Shimotsuke, Tochigi 329-0498, Japan

Full list of author information is available at the end of the article

(c) The Author(s) 2022. Open Access This article is licensed under a Creative Commons Attribution 4.0 International License, which permits use, sharing, adaptation, distribution and reproduction in any medium or format, as long as you give appropriate credit to the original author(s) and the source, provide a link to the Creative Commons licence, and indicate if changes were made. The images or other third party material in this article are included in the article's Creative Commons licence, unless indicated otherwise in a credit line to the material. If material is not included in the article's Creative Commons licence and your intended use is not permitted by statutory regulation or exceeds the permitted use, you will need to obtain permission directly from the copyright holder. To view a copy of this licence, visit http://creativecommons.org/licenses/by/4.0/. 


\section{Introduction}

Severe community-acquired pneumonia (CAP) is the most common cause of ARDS [1,2] and death [3, 4] in critically ill patients. Approximately $80 \%$ of patients with ARDS in intensive care unit required mechanical ventilation [5] and estimates of the mortality rate in cases of severe CAP-associated ARDS have been as high as approximately 50\% [2]. Strategies for treating ARDS have been investigated in many countries for reducing mortality among patients with severe CAP-associated ARDS [5].

Macrolides are a class of antibiotics that are widely used for treating CAP, and they play an important role in treating atypical pneumonia $[6,7]$. Clinical and experimental studies have shown immunomodulatory effects of macrolides, such as reduction in cytokine production, neutrophil accumulation in the airways, mucus hypersecretion, and biofilm formation, as well as the acceleration of neutrophil apoptosis [8]. These effects may reduce the risk of mortality in patients with severe pneumonia [9], and several guidelines have recommended azithromycin combined with $\beta$-lactam for patients with severe CAP [6, 7].

Only few studies have investigated the effects of macrolides on severe pneumonia-associated ARDS. Some previous studies have demonstrated that macrolides, including azithromycin therapy, may be beneficial for ARDS [10-12]. However, these studies were based on small sample size and included both patients with nonpulmonary ARDS and those with pulmonary ARDS. Therefore, it remains unknown whether azithromycin has beneficial effects in patients with CAP-associated ARDS.

This study aimed to investigate the additional effect of azithromycin when used with $\beta$-lactam compared with the effect with $\beta$-lactam alone in mechanically ventilated patients with CAP-associated ARDS, using data in the Diagnosis Procedure Combination (DPC) database, a national inpatient database in Japan.

\section{Materials and methods Database information}

The DPC database includes administrative claims data for approximately 8 million inpatients discharged per year from more than 1000 acute care hospitals in Japan. The attending physicians are required to accurately record the diagnoses because these diagnoses are linked to a health insurance payment system. The DPC database contains patient information on the following variables: demographics and selected clinical information: admission and discharge, discharge status (deceased or living), diagnoses, surgeries and procedures performed, medications administered, and special reimbursements for specific conditions. The DPC database also includes dates of procedures and the dosages and dates of all drugs administered during hospitalization $[13,14]$.

\section{Patient selection}

In this retrospective cohort study, we identified severe CAP-associated ARDS, which was defined as mechanically ventilated patients who were diagnosed with sepsis and pneumonia and received $\beta$-lactam within hospital 2 days after admission between July 2010 and March 2015. Defining sepsis was based on the previous criteria (see Additional data 1) [14, 15]. Defining pneumonia was based on ICD-10 codes J13-J18, which is listed as the primary diagnosis or as comorbidities at admission. The patients required mechanical ventilation within hospital 2 days after admission. ARDS was defined as ICD10 code $\mathrm{J} 80$ as the primary diagnosis or comorbidity at admission (Fig. 1).

The patients who meet the following criteria were excluded: <18years of age; discharge within hospital 2 days after admission; malignant neoplastic diseases; autoimmune disorders; intravenous erythromycin use within hospital 2 days after admission; and oral clarithromycin use within hospital 2 days after admission.

\section{Variables}

The azithromycin group included only patients who received intravenous or oral azithromycin within hospital 2 days after admission, whereas the control group included only patients who did not receive azithromycin within hospital 2 days after admission.

Other variables that were assessed include age, sex, hospital type, hospital volume, comorbidities at admission, the Japan Coma Scale score, the age, dehydration, respiration, orientation, and blood pressure (A-DROP) system, and need for the procedures within hospital 2 days after admission. Hospital type was categorized as academic or nonacademic. Hospital volume was defined as the average annual number of mechanically ventilated patients with CAP within hospital 2 days after admission, in each hospital. The Japan Coma Scale score was recorded for all patients at admission; the level of consciousness was assessed on admission, which correlated well with the Glasgow Coma Scale [16]. We categorized the Japan Coma Scale score into four groups: 0 (alert), 1-3 (delirium), 10-30 (somnolence), and 100-300 (coma). We used the A-DROP system to assess the severity of CAP on admission. This scoring system is similar to the CURB65 system of the British Thoracic Society and has been validated in the DPC database [17]. A-DROP severity scores were categorized into four groups: 0 (mild group), 1-2 (moderate group), 3 (severe group) and 


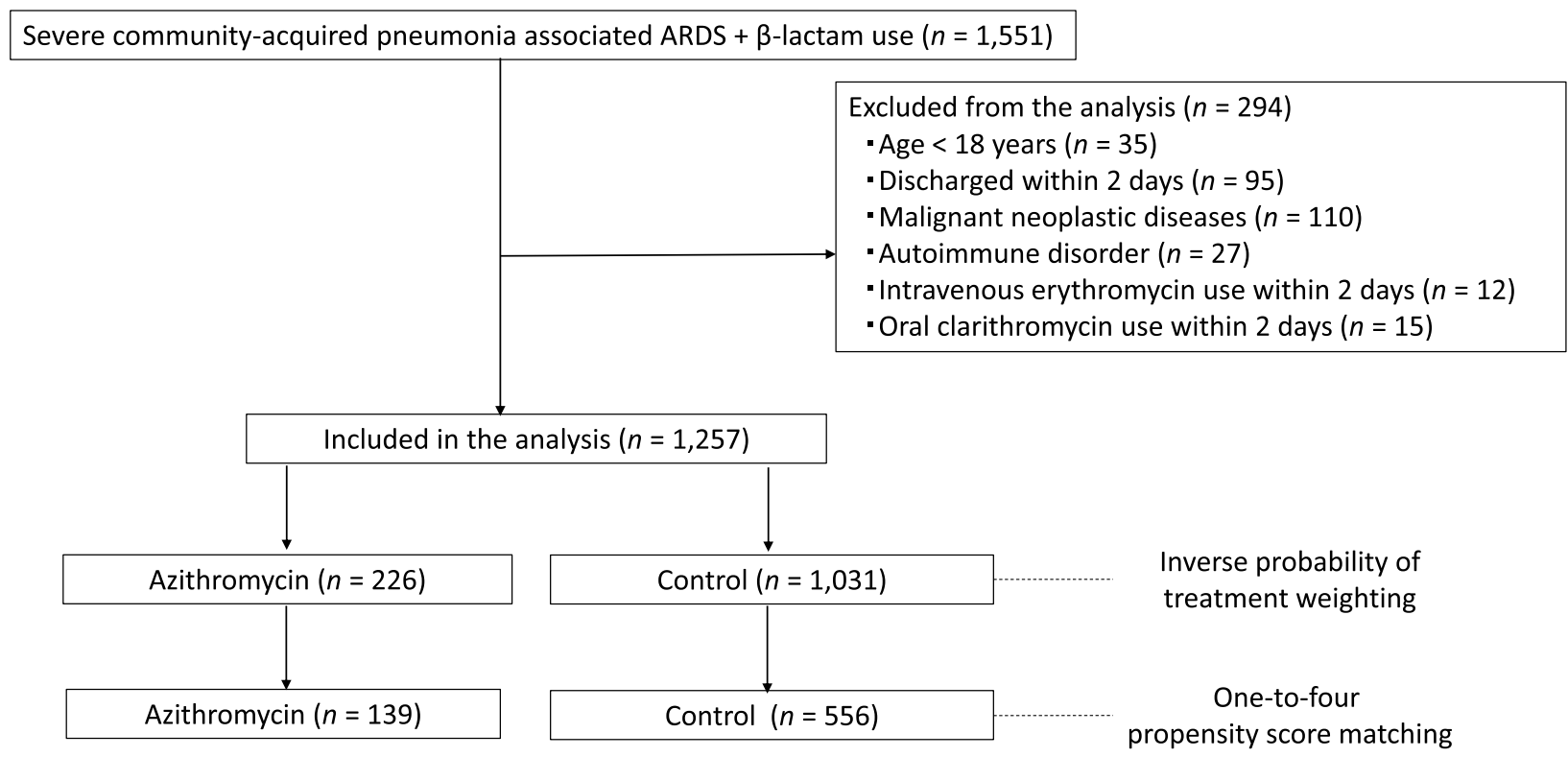

Fig. 1 Flowchart of patient selection

4-5 (extremely severe group). Mild group was defined as patients who can be treated as outpatients. Moderate group was defined as patients who may be admitted to the hospital and treated. Severe group was defined as patients who should be admitted to the hospital and treated. Extremely severe group was defined as patients who require intensive care managements. Patients with missing data on A-DROP were categorized as missing on this variable. Need for the following procedures within hospital 2 days after admission was also examined: intermittent renal replacement therapy; continuous renal replacement therapy; extracorporeal membrane oxygenation; red blood cells transfusion; platelet concentrates transfusion; fresh-frozen plasma transfusion; intravenous noradrenalin; intravenous dopamine; intravenous dexamethasone; intravenous hydrocortisone; intravenous methyl prednisolone; intravenous prednisolone; intravenous antithrombin; intravenous recombinant human soluble thrombomodulin; intravenous immunoglobulin; intravenous sivelestat sodium; primary intravenous antibiotic used, divided into Ranks 1 to 5 , drawing on a previous study [18] (see Additional data 2); intravenous anti-methicillin-resistant Staphylococcus aureus (MRSA) drugs; and intravenous fluoroquinolone.

\section{Outcome measures}

The outcomes of this study were 28-day mortality and inhospital mortality.

\section{Statistical analysis}

Descriptive data are reported as numbers and percentages for categorical variables and as means and standard deviations for continuous variables. Descriptive statistics were assessed before and after propensity score matching and after inverse probability of treatment weighting (IPTW). We performed one-to-four propensity score matching to adjust for differences in baseline characteristics and disease severity on admission between the two groups. The probability that a patient received azithromycin was adjusted for potential confounders using the following characteristics: age, sex, hospital type, hospital volume, Japan Coma Scale scores, A-DROP, comorbidities at admission, renal replacement therapy, extracorporeal membrane oxygenation, transfusion, vasopressors, intravenous steroids, intravenous immunoglobulin, intravenous antithrombin, intravenous recombinant human soluble thrombomodulin, intravenous sivelestat sodium, and Rank 1-5 antibiotics, fluoroquinolone, and antiMRSA drugs used. The following interaction terms were added to estimate the propensity score to achieve a better balance in patient characteristics between the two groups: age and mild A-DROP score, age and dopamine, age and somnolence as consciousness level and extracorporeal membrane oxygenation, and fluoroquinolone and anti-MRSA drugs. Several elements from the patients' medical histories (severe liver disease, hemiplegia, or paraplegia) and initial use of several drugs (clindamycin, aminoglycoside, tetracycline, and 
anti-fungal drugs within hospital 2 days after admission,) were not included in this analysis because they were relevant only to a few patients. We used absolute standardized mean differences and assessed the balance in patient characteristics [19]. Absolute standardized mean differences of less than 0.1 were considered negligible imbalances in baseline characteristics and disease severity on admission between the groups [20]. Fisher's exact test was performed to compare 28-day mortality and in-hospital mortality between the groups. We used IPTW to estimate the treatment effect [21]. We calculated risk differences and their 95\% CIs between the before and after propensity score-matched, and after IPTW analyses [21]. The level of statistical significance was $P<0.05$ for a two-sided test. Propensity score matching was conducted with the "matching" package, and IPTW analysis was conducted with the "survey" package in $\mathrm{R}$ statistical software, Version 3.1.3 (The R Foundation, Vienna, Austria). All other analyses were conducted using IBM SPSS, Version 25 (IBM SPSS, Armonk, NY).

\section{Results}

A total of 1257 patients with severe CAP-associated ARDS during the 57-month study period were identified in the DPC database. The eligible patients were divided into the azithromycin group $(n=226)$ and the control group $(n=1031)$. The one-to-four propensity score matching analysis included 139 azithromycin users (azithromycin group) and 556 non-users (control group).

\section{Baseline characteristics}

Table 1 reveals the baseline characteristics of the before and after propensity score-matched groups. After propensity score matching, there was adequate balance in patient characteristics between the groups.

\section{Outcome measures}

Table 2 reveals the results of 28-day mortality and in-hospital mortality in the azithromycin and control groups before and after propensity score matching. Before propensity score matching, the 28-day mortality rate was $36.3 \%$ in the azithromycin group vs. $36.9 \%$ in the control group ( $p=0.939)$, and the in-hospital mortality rate was $46.0 \%$ in the azithromycin group vs. $49.7 \%$ in the control group $(p=0.340)$. After propensity score matching, there were no significant differences between the two groups for 28 -day mortality $(34.5 \%$ vs. $37.6 \%, p=0.556)$ or inhospital mortality ( $46.0 \%$ vs. $49.1 \%, p=0.569)$. The IPTW analysis also revealed similar results (see Additional data 3 and Additional data 4).

\section{Discussion}

The present study using a DPC database showed that the addition of azithromycin to $\beta$-lactam treatment was not associated with a lower rate of 28-day mortality or inhospital mortality, compared with the rate in treatment with $\beta$-lactam alone, in mechanically ventilated patients with CAP-associated ARDS.

Several possible explanations for these results should be considered. First, the immunomodulatory effects of azithromycin may not reduce inflammatory markers associated with ARDS or mortality among mechanically ventilated patients with CAP-associated ARDS. A previous experimental study evaluated the immunomodulatory effects of macrolides using total cell count and neutrophil count in bronchoalveolar lavage fluids in mice with bleomycin-induced acute lung injury. The results showed that, compared with other macrolide drugs, azithromycin was less active in inhibiting neutrophil cells, which caused acute lung injury [22]. This may also explain our results.

Second, atypical pathogens such as Mycoplasma pneumoniae or Chlamydophila pneumoniae as target organisms of azithromycin rarely cause progression to ARDS, which may have influenced our results. Previous studies have shown that a few patients with atypical pneumonia showed progression to severe CAP or ARDS [23] and that approximately $5 \%$ of atypical organisms cause CAPassociated ARDS [24, 25]. Thus, there may have been few patients in our sample for whom $\beta$-lactam was insufficient and for whom the addition of azithromycin was effective, and this may be the reason why azithromycin did not reduce mortality in patients with CAP-associated ARDS in our study.

Third, the difference in the susceptibility of pneumonia pathogens may also explain our results. The addition of azithromycin to $\beta$-lactam has been reported to be double coverage of Streptococcus pneumoniae, which is the leading pathogen of CAP-associated ARDS [26]. However, approximately $80 \%$ of $S$. pneumoniae strains are resistant to azithromycin in Japan [2, 27]. Several guidelines recommended macrolide use for pneumonia for the following reasons except double coverage of S. pneumoniae: treating atypical pneumonia pathogens, or immunomodulatory effects $[6,7,26]$. In a population where rate of atypical pathogens, etiology, and azithromycin resistance levels differ, the value of azithromycin therapy could be higher or lower. Therefore, in Japan, the value of azithromycin therapy might be lower and avoiding the use of azithromycin as immunomodulatory effects for ARDS might also help reduce azithromycin resistance levels. 
Table 1 Patients' baseline characteristics in before and after propensity score-matched groups

\begin{tabular}{|c|c|c|c|c|c|c|}
\hline \multirow[b]{2}{*}{ Variable } & \multicolumn{2}{|c|}{$\begin{array}{l}\text { Before propensity score-matched } \\
\text { groups }\end{array}$} & \multirow[b]{2}{*}{ SMD } & \multicolumn{2}{|c|}{$\begin{array}{l}\text { After propensity score-matched } \\
\text { groups }\end{array}$} & \multirow[b]{2}{*}{ SMD } \\
\hline & $\begin{array}{l}\text { Azithromycin group } \\
n=226\end{array}$ & $\begin{array}{l}\text { Control group } \\
n=1031\end{array}$ & & $\begin{array}{l}\text { Azithromycin group } \\
n=139\end{array}$ & $\begin{array}{l}\text { Control group } \\
n=556\end{array}$ & \\
\hline Age (years), mean (SD) & $70.0(14.8)$ & $73.6(12.9)$ & 0.25 & $71.8(13.7)$ & $72.7(12.9)$ & 0.07 \\
\hline Sex (female), $n(\%)$ & $64(28.3)$ & $316(30.6)$ & 0.05 & $39(28.1)$ & $161(29.0)$ & 0.02 \\
\hline Hospital type (academic), n (\%) & $50(22.1)$ & $162(15.7)$ & 0.16 & $30(21.6)$ & $99(17.8)$ & 0.09 \\
\hline Hospital volume (cases/year), mean (SD) & $118.0(58.6)$ & $106.9(60.8)$ & 0.19 & $108.9(48.9)$ & $111.1(64.7)$ & 0.04 \\
\hline \multicolumn{7}{|l|}{ Comorbidities, $n(\%)$} \\
\hline Myocardial infarction & $3(1.3)$ & $15(1.5)$ & 0.01 & $2(1.4)$ & $3(0.5)$ & 0.09 \\
\hline Congestive heart failure & $45(19.9)$ & $239(23.2)$ & 0.08 & $33(23.7)$ & $122(21.9)$ & 0.04 \\
\hline Peripheral vascular disease & $7(3.1)$ & $11(1.1)$ & 0.14 & $3(2.2)$ & $9(1.6)$ & 0.04 \\
\hline Cerebrovascular disease & $9(4.0)$ & $69(6.7)$ & 0.12 & $8(5.8)$ & $34(6.1)$ & 0.02 \\
\hline Dementia & $1(0.4)$ & $25(2.4)$ & 0.17 & $1(0.7)$ & $3(0.5)$ & 0.02 \\
\hline Chronic pulmonary disease & $18(8.0)$ & $93(9.0)$ & 0.04 & $11(7.9)$ & $51(9.2)$ & 0.05 \\
\hline Peptic ulcer & $6(2.7)$ & $34(3.3)$ & 0.04 & $4(2.9)$ & $15(2.7)$ & 0.01 \\
\hline Mild liver disease & $7(3.1)$ & $29(2.8)$ & 0.02 & $4(2.9)$ & $17(3.1)$ & 0.01 \\
\hline Diabetes without chronic complications & $30(13.3)$ & $164(15.9)$ & 0.08 & $21(15.1)$ & $82(14.7)$ & 0.01 \\
\hline Diabetes with chronic complications & $12(5.3)$ & $48(4.7)$ & 0.03 & $8(5.8)$ & $26(4.7)$ & 0.05 \\
\hline Renal disease & $12(5.3)$ & $74(7.2)$ & 0.08 & $10(7.2)$ & $37(6.7)$ & 0.02 \\
\hline \multicolumn{7}{|l|}{ Consciousness level, $n(\%)$} \\
\hline Alert & $136(60.2)$ & $517(50.1)$ & 0.20 & 79 (56.8) & $307(55.2)$ & 0.03 \\
\hline Delirium & $48(21.2)$ & $232(22.5)$ & 0.03 & $32(23.0)$ & $120(21.6)$ & 0.04 \\
\hline Somnolence & $11(4.9)$ & $100(9.7)$ & 0.19 & $9(6.5)$ & $34(6.1)$ & 0.02 \\
\hline Coma & $26(11.5)$ & $149(14.5)$ & 0.09 & $17(12.2)$ & $78(14.0)$ & 0.05 \\
\hline \multicolumn{7}{|l|}{ A-DROP category, $n(\%)$} \\
\hline Mild & $1(0.3)$ & $5(0.5)$ & 0.01 & $0(0.0)$ & $2(0.4)$ & 0.09 \\
\hline Moderate & $28(12.4)$ & $83(8.1)$ & 0.14 & $14(10.1)$ & $54(9.7)$ & 0.01 \\
\hline Severe & $19(8.4)$ & $86(8.3)$ & $<0.01$ & $12(8.6)$ & $50(9.0)$ & 0.01 \\
\hline Extremely severe & $25(11.1)$ & $185(17.9)$ & 0.20 & $17(12.2)$ & $84(15.1)$ & 0.08 \\
\hline Missing & $154(68.1)$ & $677(65.7)$ & 0.05 & $96(69.1)$ & $368(66.2)$ & 0.06 \\
\hline \multicolumn{7}{|l|}{ Intervention, $n(\%)$} \\
\hline Renal replacement therapy & $36(15.9)$ & $102(9.9)$ & 0.18 & $15(10.8)$ & 59 (10.6) & 0.01 \\
\hline Extracorporeal membrane oxygenation & $14(6.2)$ & $9(0.9)$ & 0.29 & $1(0.7)$ & $3(0.5)$ & 0.02 \\
\hline \multicolumn{7}{|l|}{ Catecholamines, $n(\%)$} \\
\hline Dopamine & $55(24.3)$ & $373(36.2)$ & 0.26 & $37(26.6)$ & $169(30.4)$ & 0.08 \\
\hline Noradrenaline & $101(44.7)$ & $344(33.4)$ & 0.23 & $52(37.4)$ & $212(38.1)$ & 0.02 \\
\hline \multicolumn{7}{|l|}{ Transfusion, $n$ (\%) } \\
\hline Red cell transfusion & $18(8.0)$ & $97(9.4)$ & 0.05 & $12(8.6)$ & $40(7.2)$ & 0.05 \\
\hline Platelets transfusion & $7(3.1)$ & $34(3.3)$ & 0.01 & $1(0.7)$ & $10(1.8)$ & 0.09 \\
\hline Fresh frozen plasma transfusion & $4(1.8)$ & $41(4.0)$ & 0.13 & $2(1.4)$ & $8(1.4)$ & $<0.01$ \\
\hline \multicolumn{7}{|l|}{ Other treatment, $n(\%)$} \\
\hline Antithrombin & $30(13.3)$ & $92(8.9)$ & 0.14 & $12(8.6)$ & $47(8.5)$ & 0.01 \\
\hline Recombinant human soluble thrombomodulin & $36(15.9)$ & $92(8.9)$ & 0.21 & $11(7.9)$ & $58(10.4)$ & 0.09 \\
\hline Immunoglobulin & $54(23.9)$ & $238(23.1)$ & 0.02 & $36(25.9)$ & $126(22.7)$ & 0.08 \\
\hline Sivelestat sodium & $101(44.7)$ & $532(51.6)$ & 0.14 & $68(48.9)$ & $259(46.6)$ & 0.05 \\
\hline Steroid & $108(47.8)$ & $458(44.4)$ & 0.07 & $60(43.2)$ & $251(45.1)$ & 0.04 \\
\hline \multicolumn{7}{|l|}{ Initial antibiotic, $n(\%)$} \\
\hline Rank 5 & $110(48.7)$ & $586(56.8)$ & 0.16 & $73(52.5)$ & $286(51.4)$ & 0.02 \\
\hline Rank 4 & $63(27.9)$ & $246(23.9)$ & 0.09 & $41(29.5)$ & $149(26.8)$ & 0.06 \\
\hline
\end{tabular}


Table 1 (continued)

\begin{tabular}{|c|c|c|c|c|c|c|}
\hline \multirow[b]{3}{*}{ Variable } & \multicolumn{2}{|c|}{$\begin{array}{l}\text { Before propensity score-matched } \\
\text { groups }\end{array}$} & \multirow{3}{*}{ SMD } & \multicolumn{2}{|c|}{$\begin{array}{l}\text { After propensity score-matched } \\
\text { groups }\end{array}$} & \multirow{3}{*}{ SMD } \\
\hline & Azithromycin group & Control group & & Azithromycin group & Control group & \\
\hline & $n=226$ & $n=1031$ & & $n=139$ & $n=556$ & \\
\hline Rank 3 & $63(27.9)$ & $164(15.9)$ & 0.29 & $27(19.4)$ & $119(21.4)$ & 0.05 \\
\hline Rank 2 & $27(11.9)$ & $153(14.8)$ & 0.09 & $18(12.9)$ & $76(13.7)$ & 0.02 \\
\hline Rank 1 & $7(3.1)$ & $31(3.0)$ & 0.01 & $3(2.2)$ & $12(2.2)$ & $<0.01$ \\
\hline Anti-MRSA drug & $18(8.0)$ & $79(7.7)$ & 0.01 & $12(8.6)$ & $36(6.5)$ & 0.08 \\
\hline Fluoroquinolone & $37(16.4)$ & $376(36.5)$ & 0.47 & $34(24.5)$ & $121(21.8)$ & 0.06 \\
\hline
\end{tabular}

Abbreviations: A-DROP severity score consisting of age, dehydration, respiration, orientation, and blood pressure, MRSA methicillin-resistant Staphylococcus aureus, SD standard deviation, SMD standardized mean difference

Table 2 Twenty-eight-day mortality and in-hospital mortality in before and after propensity score-matched groups

\begin{tabular}{|c|c|c|c|c|c|c|}
\hline & \multicolumn{3}{|c|}{ Before propensity-score matched group } & \multicolumn{3}{|c|}{ After propensity-score matched group } \\
\hline & Azithromycin group & Control group & $\mathbf{P}$ & $\begin{array}{l}\text { Azithromycin } \\
\text { group }\end{array}$ & Control group & $\mathbf{P}$ \\
\hline Outcome, $n$ & 226 & 1031 & & 139 & 556 & \\
\hline Twenty-eight-day mortality, $n$ (\%) & $82(36.3)$ & $380(36.9)$ & 0.939 & $48(34.5)$ & $209(37.6)$ & 0.556 \\
\hline In-hospital mortality, n (\%) & $104(46.0)$ & $512(49.7)$ & 0.340 & $64(46.0)$ & $273(49.1)$ & 0.569 \\
\hline
\end{tabular}

Several strengths exist in this study. First, the results of our study was conducted in a real-world clinical setting in Japan. Second, our study included approximately $50 \%$ of inpatients who were admitted to acute care hospitals in Japan during the 57-month study period. Third, this is the first study to research the effect of azithromycin in mechanically ventilated patients with CAP-associated ARDS to the best of our knowledge.

Several limitations also exist in this study. First, the DPC database lacks detailed clinical data such as information on vital signs, results of blood tests, which may have biased the results. Second, the DPC database lacks of information on blood or respiratory cultures of the organisms that caused CAP-associated ARDS and the lack of the information may have influenced the results. Third, the antibiotic susceptibilities of organisms that caused CAP-associated ARDS may differ between Japan and other countries. Therefore, our results might not be generalizable to other countries. Fourth, the DPC database lacks data on the mechanical ventilation setting. Therefore, we did not have information on the severity of ARDS based on the Berlin criteria, which may have biased the results. Fifth, our study included ventilated patients with ARDS; however, we did not include ARDS patients, and the results may be different between ventilator or non-ventilator required ARDS. Sixth, the DPC database lacks detailed clinical data such as pneumococcal vaccine and rate of pneumococcal vaccination in
Japan may differ from abroad, which may be biased the results. Finally, we conducted propensity score matching analysis and IPTW to adjust for patient background characteristics and there was adequate balance in patient characteristics between the azithromycin group and the control group in this study. One of the assumption using propensity score matching analysis is the strongly ignorable treatment assignment. If there are the strongly ignorable treatment assignment and no unmeasured confounders, conditioning on the propensity score can result in unbiased estimates of average treatment effects. However, this assumption is untestable, and the confounding due to unmeasured covariates cannot be avoided completely. Therefore, the confounding due to unmeasured covariates may have biased the results.

\section{Conclusions}

This Japanese nationwide inpatient database showed that the addition of azithromycin to $\beta$-lactam treatment was not associated with a lower rate of 28-day mortality or inhospital mortality compared with the rate in treatment with $\beta$-lactam alone in mechanically ventilated patients with CAP-associated ARDS. There is not a strong enough rationale to recommend or not to recommend the use of azithromycin for ARDS to clinical guidelines, and further clinical studies are needed to confirm this result. 


\begin{abstract}
Abbreviations
A-DROP: Age; : dehydration; : respiration; : orientation; : and blood pressure; ARDS: Acute respiratory distress syndrome; CAP: Community-acquired pneumonia; DPC: Diagnosis Procedure Combination; ICD-10: International Classification of Diseases, Tenth Revision; IPTW: Inverse probability of treatment weighting; MRSA: Methicillin-resistant Staphylococcus aureus; SD: Standard deviation; SMD: Standardized mean difference.
\end{abstract}

\section{Supplementary Information}

The online version contains supplementary material available at https://doi. org/10.1186/s41479-021-00093-8.

\section{Additional file 1: Data 1. ICD-10 codes for sepsis \\ Additional file 2: Data 2. Classification of $\beta$-lactam antibiotics. Additional file 3: Table 3. Patients' characteristics in the IPTW analysis groups.}

Additional file 4: Table 4. Risk differences for 28-day mortality and inhospital mortality in the unmatched, propensity score-matched, and IPTW analysis groups.

\section{Acknowledgments \\ Not applicable.}

\section{Authors' contributions}

All authors contributed the design of the study. $\mathrm{HY}$ and $\mathrm{KF}$ take responsibility for the integrity of the data. JS, YS, HM, and HY ensured the accuracy of the data analysis. JS wrote the manuscript, and YS helped to revise the manuscript. $\mathrm{SH}, \mathrm{HM}, \mathrm{TS}, \mathrm{YM}, \mathrm{TY}, \mathrm{KF}$, and HY directly participated in the planning, execution, and analysis of the study. All authors read and approved the final manuscript. All authors meet the ICMJE authorship criteria.

\section{Funding}

This work was supported by grants from the Ministry of Health, Labour and Welfare, Japan (H30-Policy-Designated-004 and H29-ICT-General-004) and the Ministry of Education, Culture, Sports, Science and Technology, Japan (17H04141).

\section{Availability of data and materials}

The datasets used and analyzed during the current study are not publicly available for ethical reasons as the data are patient data. The data are available to interested researchers on reasonable request to the corresponding author, pending ethical approval.

\section{Declarations}

\section{Ethics approval and consent to participate}

The study was approved by the Institutional Review Board of the University of Tokyo. The requirement for patient informed consent was waived because of the anonymous nature of the data.

\section{Consent for publication}

Not applicable.

\section{Competing interests}

All authors declare that they have no competing interests.

\section{Author details}

${ }^{1}$ Division of Infectious Diseases, Jichi Medical University Hospital, 3311-1 Yakushiji, Shimotsuke, Tochigi 329-0498, Japan. ${ }^{2}$ Center for Data Science, Jichi Medical University, 3311-1 Yakushiji, Shimotsuke, Tochigi 329-0498, Japan. ${ }^{3}$ Division of General Medicine, Jichi Medical University, 3311-1 Yakushiji, Shimotsuke, Tochigi 329-0498, Japan. ${ }^{4}$ Department of Clinical Epidemiology and Health Economics, School of Public Health, The University of Tokyo, 7-3-1 Hongo, Bunkyo-ku, Tokyo 113-0033, Japan. ${ }^{5}$ Department of Infection and Immunity, School of Medicine, Jichi Medical University, 3311-1 Yakushiji, Shimotsuke, Tochigi 329-0498, Japan. ${ }^{6}$ Department of Clinical Laboratory
Medicine, Jichi Medical University, 3311-1 Yakushiji, Shimotsuke, Tochigi 329-0498, Japan. 7 Department of Health Policy and Informatics, Tokyo Medical and Dental University Graduate School of Medicine, 1-5-45, Yushima, Bunkyo-ku, Tokyo 113-8510, Japan.

Received: 5 August 2021 Accepted: 12 December 2021

Published online: 10 January 2022

\section{References}

1. Pham T, Rubenfeld GD. Fifty years of research in ARDS. The epidemiology of acute respiratory distress syndrome. A 50th birthday review. Am J Respir Crit Care Med. 2017;195(7):860-70.

2. Kao KC, Hu HC, Hsieh MJ, Tsai YH, Huang CC. Comparison of communityacquired, hospital-acquired, and intensive care unit-acquired acute respiratory distress syndrome: a prospective observational cohort study. Crit Care. 2015;19:384

3. Sligl WI, Marrie TJ. Severe community-acquired pneumonia. Crit Care Clin. 2013:29(3):563-601.

4. Musher DM, Thorner AR. Community-acquired pneumonia. N Engl J Med. 2014;371(17):1619-28.

5. Bellani G, Laffey JG, Pham T, Fan E, Brochard L, Esteban A, et al. Epidemiology, patterns of care, and mortality for patients with acute respiratory distress syndrome in intensive care units in 50 countries. JAMA. 2016 Feb;315(8):788-800.

6. Mandell LA, Wunderink RG, Anzueto A, Bartlett JG, Campbell GD, Dean NC, et al. Infectious Diseases Society of America/American Thoracic Society consensus quidelines on the management of community-acquired pneumonia in adults. Clin Infect Dis. 2007;44(Suppl 2):S27-72.

7. Mikasa K, Aoki N, Aoki Y, Abe S, Iwata S, Ouchi K, et al. JAID/JSC guidelines for the treatment of respiratory infectious diseases: the Japanese Association for Infectious Diseases/Japanese Society of Chemotherapy guide to clinical management of infectious disease/guideline-preparing committee respiratory infectious disease WG. J Infect Chemother. 2016;22(7 Suppl):S1-65

8. Corrales-Medina VF, Musher DM. Immunomodulatory agents in the treatment of community-acquired pneumonia: a systematic review. J Inf Secur. 2011;63(3):187-99.

9. Sligl WI, Asadi L, Eurich DT, Tjosvold L, Marrie TJ, Majumdar SR. Macrolides and mortality in critically ill patients with community-acquired pneumonia: a systematic review and meta-analysis. Crit Care Med. 2014;42(2):420-32.

10. Kawamura K, Ichikado K, Takaki M, Sakata Y, Yasuda Y, Shingu N, et al. Efficacy of azithromycin in sepsis-associated acute respiratory distress syndrome: a retrospective study and propensity score analysis. Springerplus. 2016;5(1):1-7.

11. Walkey AJ, Wiener RS. Macrolide antibiotics and survival in patients with acute lung injury. Chest. 2012;141(5):1153-9.

12. Kawamura K, Ichikado K, Takaki M, Eguchi Y, Anan K, Suga M. Adjunctive therapy with azithromycin for moderate and severe acute respiratory distress syndrome: a retrospective, propensity score-matching analysis of prospectively collected data at a single center. Int J Antimicrob Agents. 2018;51(6):918-24.

13. Matsuda S, Fujimori K, Kuwabara K, Ishikawa KB, Fushimi K. Diagnosis procedure combination as an infrastructure for the clinical study. Asian Pacific J Dis Manag. 2011:5(4):81-7.

14. Yamana $\mathrm{H}$, Horiguchi $\mathrm{H}$, Fushimi $\mathrm{K}$, Yasunaga $\mathrm{H}$. Comparison of procedure-based and diagnosis-based identifications of severe sepsis and disseminated intravascular coagulation in administrative data. J Epidemiol. 2016:26(10):530-7.

15. Angus DC, Linde-Zwirble WT, Lidicker J, Clermont G, Carcillo J, Pinsky MR. Epidemiology of severe sepsis in the United States: analysis of incidence, outcome, and associated costs of care. Crit Care Med. 2001;29(7):1303-10.

16. Shigematsu K, Nakano H, Watanabe $Y$. The eye response test alone is sufficient to predict stroke outcome-reintroduction of Japan coma scale: a cohort study. BMJ Open. 2013;3(4):e002736.

17. Uematsu H, Kunisawa S, Sasaki N, Ikai H, Imanaka Y. Development of a risk-adjusted in-hospital mortality prediction model for communityacquired pneumonia: a retrospective analysis using a Japanese administrative database. BMC Pulm Med. 2014;14:203. 
18. Yamana H, Matsui H, Tagami T, Hirashima J, Fushimi K, Yasunaga H. De-escalation versus continuation of empirical antimicrobial therapy in community-acquired pneumonia. J Inf Secur. 2016;73(4):314-25.

19. Griswold ME, Russell Localio A, Mulrow C. Propensity score adjustment with multilevel data: setting your sites on decreasing selection bias. Ann Intern Med. 2010;152(6):393-5

20. Austin PC. Balance diagnostics for comparing the distribution of baseline covariates between treatment groups in propensity-score matched samples. Stat Med. 2009;28(25):3083-107.

21. Austin PC. Variance estimation when using inverse probability of treatment weighting (IPTW) with survival analysis. Stat Med. 2016;35(30):5642-55

22. Kawashima M, Yatsunami J, Fukuno Y, Nagata M, Tominaga M, Hayashi S. Inhibitory effects of 14-membered ring macrolide antibiotics on bleomycin-induced acute lung injury. Lung. 2002;180(2):73-89.

23. Miyashita N, Obase Y, Ouchi K, Kawasaki K, Kawai Y, Kobashi Y, et al. Clinical features of severe mycoplasma pneumoniae pneumonia in adults admitted to an intensive care unit. J Med Microbiol. 2007:56(12):1625-9.

24. Kohno S, Seki M, Takehara K, Yamada Y, Kubo K, Ishizaka A, et al. Prediction of requirement for mechanical ventilation in community-acquired pneumonia with acute respiratory failure: a multicenter prospective study. Respiration. 2013;85(1):27-35.

25. Cilloniz C, Ferrer M, Liapikou A, Garcia-Vidal C, Gabarrus A, Ceccato A, et al. Acute respiratory distress syndrome in mechanically ventilated patients with community-acquired pneumonia. Eur Respir J. 2018;51(3):1702215.

26. Parnham MJ, Haber VE, Giamarellos-Bourboulis EJ, Perletti G, Verleden GM, Vos R. Azithromycin: mechanisms of action and their relevance for clinical applications. Pharmacol Ther. 2014;143(2):225-45.

27. Yanagihara K, Matsumoto T, Aoki N, Sato J, Wakamura T, Kiyota H, et al. Nationwide surveillance of bacterial respiratory pathogens conducted by the surveillance committee of Japanese Society of Chemotherapy, the Japanese Association for Infectious Diseases, and the Japanese Society for Clinical Microbiology in 2014. J Infect Chemother. 2019;25(9):657-68.

\section{Publisher's Note}

Springer Nature remains neutral with regard to jurisdictional claims in published maps and institutional affiliations.

Ready to submit your research? Choose BMC and benefit from:

- fast, convenient online submission

- thorough peer review by experienced researchers in your field

- rapid publication on acceptance

- support for research data, including large and complex data types

- gold Open Access which fosters wider collaboration and increased citations

- maximum visibility for your research: over $100 \mathrm{M}$ website views per year

At BMC, research is always in progress.

Learn more biomedcentral.com/submissions 